International Journal of Advanced Academic Research (Sciences, Technology and Engineering) | ISSN: 2488-9849

Vol. 6, Issue 10 (October, 2020) | www.ijaar.org

Journal DOI: 10.46654/ij.24889849

Article DOI: 10.46654/ij.24889849.e6105

\title{
EFFECTS OF ALKALI MODIFICATION ON THE TENSILE PROPERTIES OF NIGERIAN SISAL FIBRES
}

\author{
E.S. Nwadiokwu \\ Chemical, Fibre and Environmental Technology Department, \\ Federal Institute of Industrial Research, Oshodi, \\ P.M.B. 21023, Ikeja, Lagos, Nigeria. \\ esnwadiokwu@gmail.com
}

\begin{abstract}
The effects of alkali modification on the tensile properties of sisal fibres have been investigated. The sisal fibres were chemically modified using different concentrations of caustic soda(5\%, $10 \%, 15 \%$ and 20\%) while varying the treatment time (5, 10and 15 minutes). Treated and untreated samples were assessed for their tensile properties at four different gauge lengths using the Instron tensile tester. The results obtained show that alkali modification had appreciable effect on the tensile properties of the sisal fibres. Tenacity, Work of rupture and breaking extension increased with increasing concentrations of caustic soda while Young's modulus decreased. However, these tensile properties decreased with increased gauge length due to the "weak-link effect". The time of treatment had no significant effect on all the properties investigated.
\end{abstract}

KEYWORDS: Alkali treatment, Sisal fibre, weak link effect, gauges length. 


\subsection{INTRODUCTION}

Plant fibres are rich in cellulose and they are a cheap, easily renewable source of fibres with the potential for polymer reinforcement. The attractive features of these fibres are their light weight, and non-toxicity (Abdelmouleh et al., 2007; Tserki et al., 2005). Though Sisal fibre is one of the most widely used natural fibres (Li et al., 2000) and accounts for almost half the total production of natural fibres, a large quantity of this economic and renewable resource is still underutilized. Severalscientific studies have been performed on alkali treatment of sisal fibres (Joseph et al, 2000; Streekalaet al, 2001; Morrison et al., 2000; Mishra et al., 2002).

These previous studies showed that that alkalization leads to an increase in the amount of amorphous cellulose at the cost of crystalline cellulose. Also, the structure of sisal fibre can be chemically modified to attain properties that can promote the development of fibre-resin adhesion, leading to an increase in the interfacial energy and hence, improvement in their tensile properties.

In the study reported in this paper, alkali treatment was employed to chemically modify sisal fibres using different concentrations of $\mathrm{NaOH}(5 \%, 10 \%, 15 \%$ and $20 \%)$ and at different timing (5mins, 10mins and 15mins). The effects of this modification on the tensile properties were assessed and analysed.

\subsection{MATERIALS AND METHODS \\ 2.1 Sisal Fibres}

The sisal fibres used for this study were obtained from the Botanical Garden of the Ahmadu Bello University, Zaria.

\subsection{Chemicals}

Chemicals used are: Aqueous sodium hydroxide solution $(5,10,15$ and $20 \%$ by weight $)$ and acetic acid ( $2 \%$ by weight).

\subsection{Equipment/Instrumentation}

The following equipment/instruments were used for the study: Instron Tensile Tester (model 1025), oven, digital weighing balance, basic laboratory glass wares such as, conical flasks, beakers, measuring cylinders, thermometer, stirring rod and volumetric flask.

\subsection{METHODS}

\subsubsection{Extraction of the Sisal Fibres}

Theleaves were crushed and beaten manually by a smooth edged stick so that only fibres remain. After extraction, the fibres were washed thoroughly in plenty of water to remove surplus wastes such as chlorophyll, leaf juices and adhesive solids (hemicelluloses). The fibres were then dried in open air. Dried sisal fibre strands are usually creamy white in colour. 


\subsubsection{Alkali Treatment of the Fibres}

2 grams each of the sisalfibres weresoaked in 5, 10, 15 and 20\% $\mathrm{NaOH}$ solution for 5, 10 and 15 minutes at a temperature of $65^{\circ} \mathrm{C}$. These fibres were further rinsed with water followed by neutralization in $2 \%$ acetic acid solution. The fibre were then finally rinsed in water and then dried at room temperature.

Sisal-OH $+\mathrm{NaOH} \rightarrow$ Sisal- $\mathrm{O}^{-} \mathrm{Na}^{+}+\mathrm{H}_{2} \mathrm{O}$

\subsubsection{DETERMINATION OF TENSILE PROPERTIES}

The tensile properties of treated and untreated sisal fibres were determined. The following tensile properties were determined using the Instron tensile tester; tenacity, percentage extension, initial Young's modulus and Work of rupture. For all samples, the stress-strain curves were obtained at four different gauge lengths $(10 \mathrm{~cm}, 15 \mathrm{~cm}, 20 \mathrm{~cm}$ and $25 \mathrm{~cm})$. The rate of extension was $25 \%$ per minute and a maximum load of $50 \mathrm{~kg}$ was used for all tests. Cross head speed was $50 \mathrm{~mm}$ per minute and chart speed was $50 \mathrm{~mm}$ per minute. The tenacity and percentage extensionwere calculated using the following relationships:

Percentage extension $=\frac{\text { elongation }}{\text { initiallength }} \times \mathbf{1 0 0}(\%)$

Tenacity $=\frac{\text { Load }}{\text { Mass /Unitlengt } h} \mathrm{~N} /$ tex

Linear density in Tex $=\frac{w x 1000}{100 L}$

Where $\mathrm{w}=$ weight of the fibre, $\mathrm{L}=$ length of the fibre used

The work of rupture was obtained by calculating the area under the stress-strain curve.

The counting of squares method was used; thus:

Work of Rupture $=\frac{(\text { averagestrengt } h g m)(\text { utimateelonga } \text { tion }(\%)}{\text { Denier }(100)}$

The Young's initial modulus which is the slope of the stress-strain curve at the origin (after the removal of any crimp) was measured for each sample. 
Journal DOI: 10.46654/ij.24889849

Vol. 6, Issue 10 (October, 2020) | www.ijaar.org

\subsubsection{EFFECT OF CONCENTRATION OF CAUSTIC SODA AND TREATMENT TIME}

The effects of the concentration of the $\mathrm{NaOH}$ and the duration of treatment on the tensile properties of the sisal fibres were investigated and appropriategraphs plotted from the results.

\subsection{RESULTS AND DISCUSSION}

Figures 1 to 7 show the graphs of the various tensile properties (tenacity, breaking extension, initial Young's modulus and the work of rupture) plotted against gauge lengths and the effects of varied times at constant concentration and varied concentrations at constant time on the sisal fibre was deduced from the graphs.

\subsection{FIBRE TENACITY}

\section{(Tenacities at different concentrations, different gauge lengths, but at constant time)}

Figure 1 shows that there are differences between the untreated and treated sisal fibres as the modified onesincreased in their tenacities compared to the unmodified ones.The higher the alkali concentration, the higher their tenacities.However, both the tenacityof the unmodified and modified fibres decreased with increase in gauge lengths. This is attributable to the "weak-link effect". It can be said that the higher tenacities of the modified fibres as compared to the untreated ones, may be due to the increase in strength caused by the increase in concentrations of alkali whichimproves the adhesivecharacteristics of fibre surface by removing the inherent constituents (lignin, pectins, hemicelluloses etc) thereby producing a rough surface topography. In addition, alkali modification leads to fibre fibrillation, i.e. breakingdown of the fibre bundles into smaller fibrils and consequently increases the fibre tenacity. 


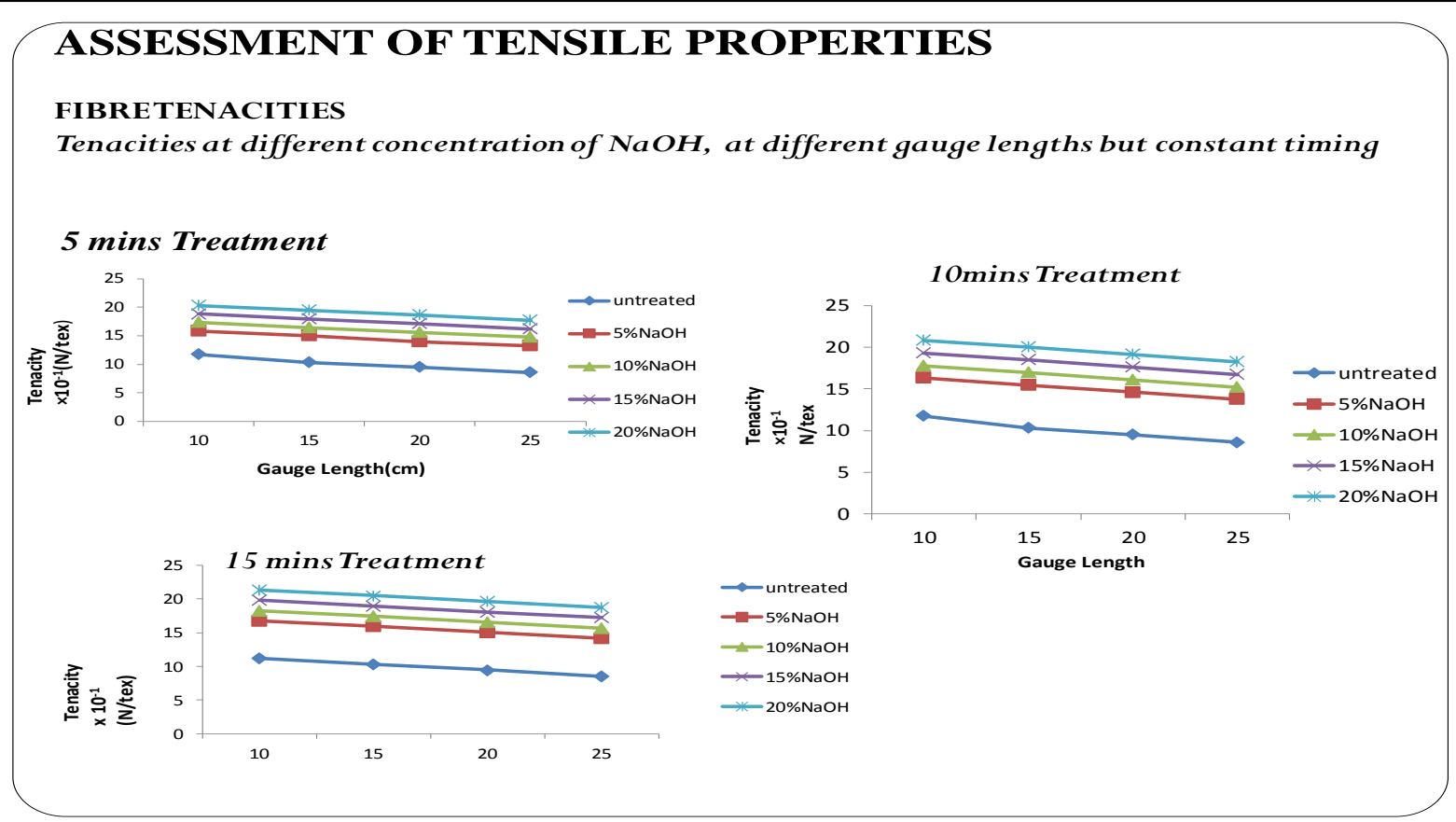

Figure 1: Fibre tenacity at different concentrations of $\mathrm{NaOH}$, different gauge lengths but constant time.

\subsection{FIBRE TENACITY}

\section{(Tenacities at different time, different gauge length, but at constant concentration)}

Figure 2 show the various graphsof tenacity versus gauge length at constant concentration with different time range. It can be noticed that there is a wide gap in tenacity between the untreated and treated fibres, however thedifferences in the time of modifications has little effect on the modified fibres at constant concentration. This is attributable to the fact that the modification was almost instantaneous at theoptimum treatment temperature of $65^{\circ} \mathrm{C}$. This is to show that increase in the time of alkali modification does not really have marked effect on the fibre tenacity. It is also noticed that the increase in gauge length caused the tenacities to decrease. This is also due to the "weak-link effect" as mentioned earlier. 


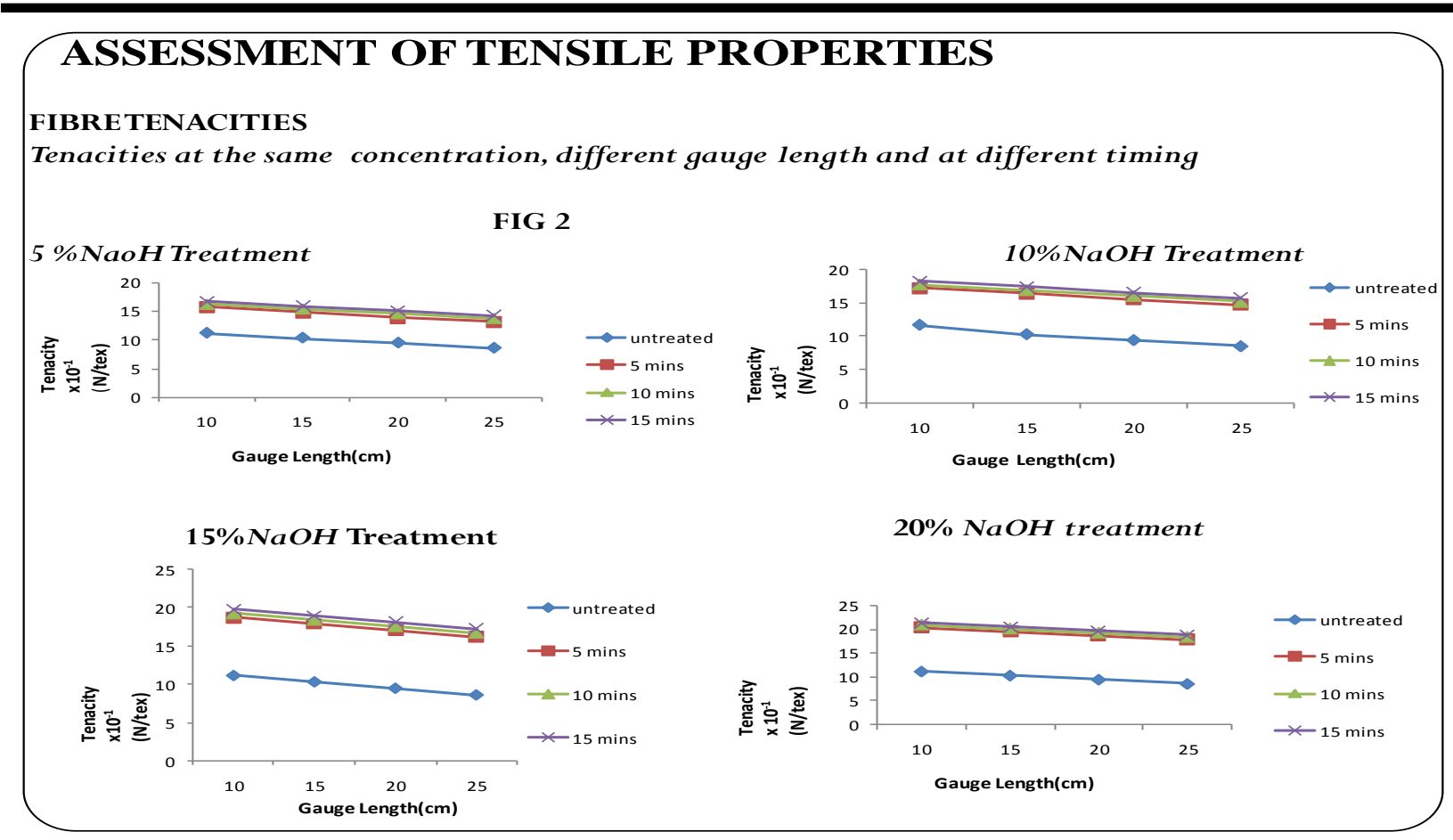

Figure 2 : Fibre tenacity at the same concentrations of $\mathrm{NaOH}$, different gauge lengths atdifferent time.

\subsection{BREAKING EXTENSION}

(Breaking extension at different concentrations, different gauge lengths, but at constant time)

Figure 3 show that the modified samples have higher breaking extension than the untreated ones. This trend is generally expected of untreated sisal fibre because of its natural hardness and high weight. This is due to the presence of its constituents such as (lignin, pectins, hemicelluloses etc.) as a result they are less extensible.

However, after alkali modification, the sisal fibre becomes lighter due to the reduction in weight and diameter making it more extensible. This is attributable to the removal of these constituents and depends on the extent of the modification. Therefore increase in concentrations of $\mathrm{NaOH}$, leads to increase in breaking extension of the fibres. The breaking extension decreased with increasing gauge length due to the weak-link effect. 


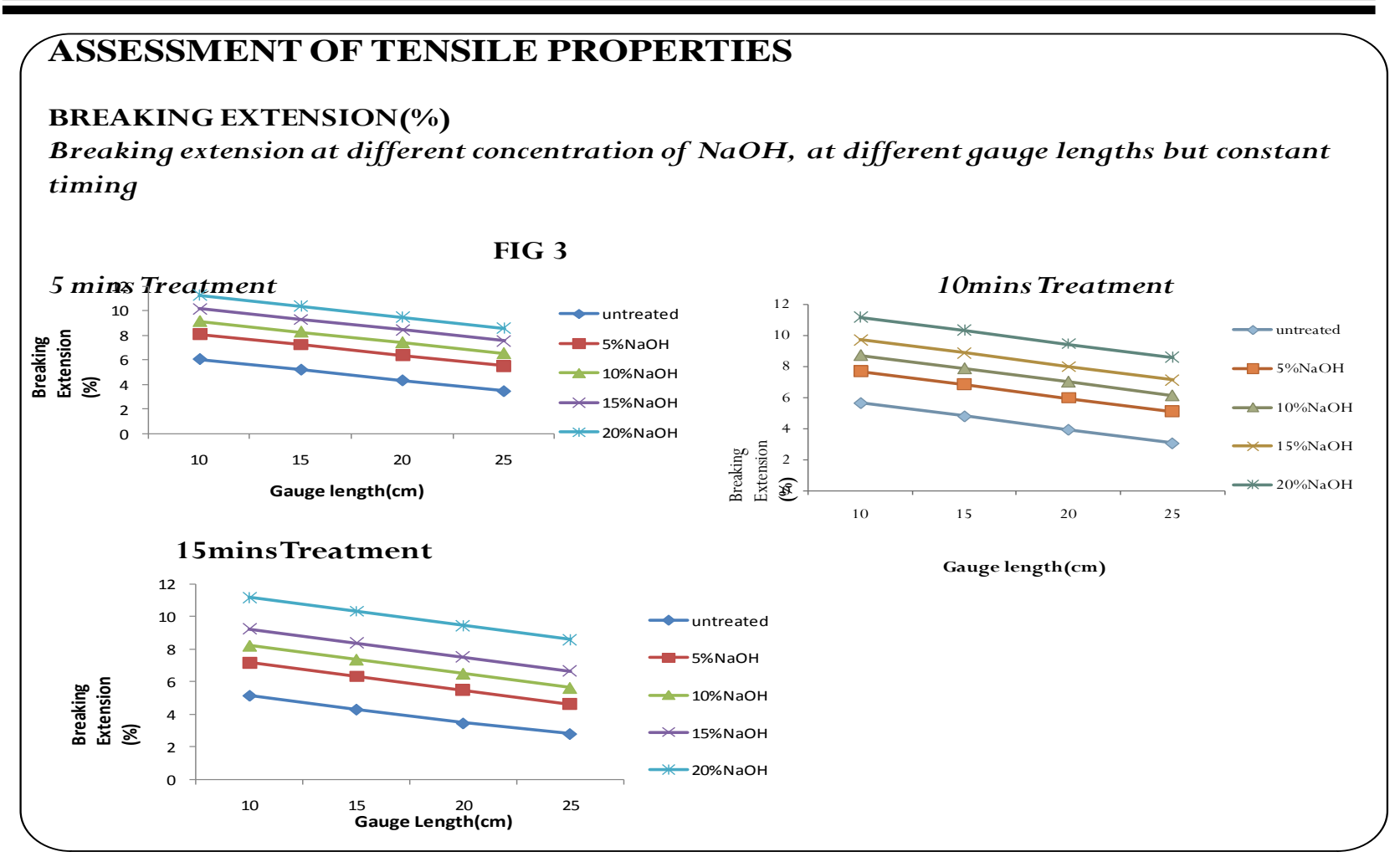

Figure 3: Breaking Extension at different concentration of $\mathrm{NaOH}$, different gauge lengths at constant time.

\subsection{BREAKING EXTENSION}

(Breaking extension at constant concentration, different gauge length, and at different time)

The figure 4 shows that increase in the time of modification has little effect on the breaking extension of the sisal fibres as compared to the increase in concentration. This is also attributable to the almost instant modification at the optimum temperature of $65^{\circ} \mathrm{C}$ as explained earlier. The reduction in tenacities with increasing gauge length is also due to the weak link effect. 
Journal DOI: 10.46654/ij.24889849

Vol. 6, Issue 10 (October, 2020) | www.ijaar.org

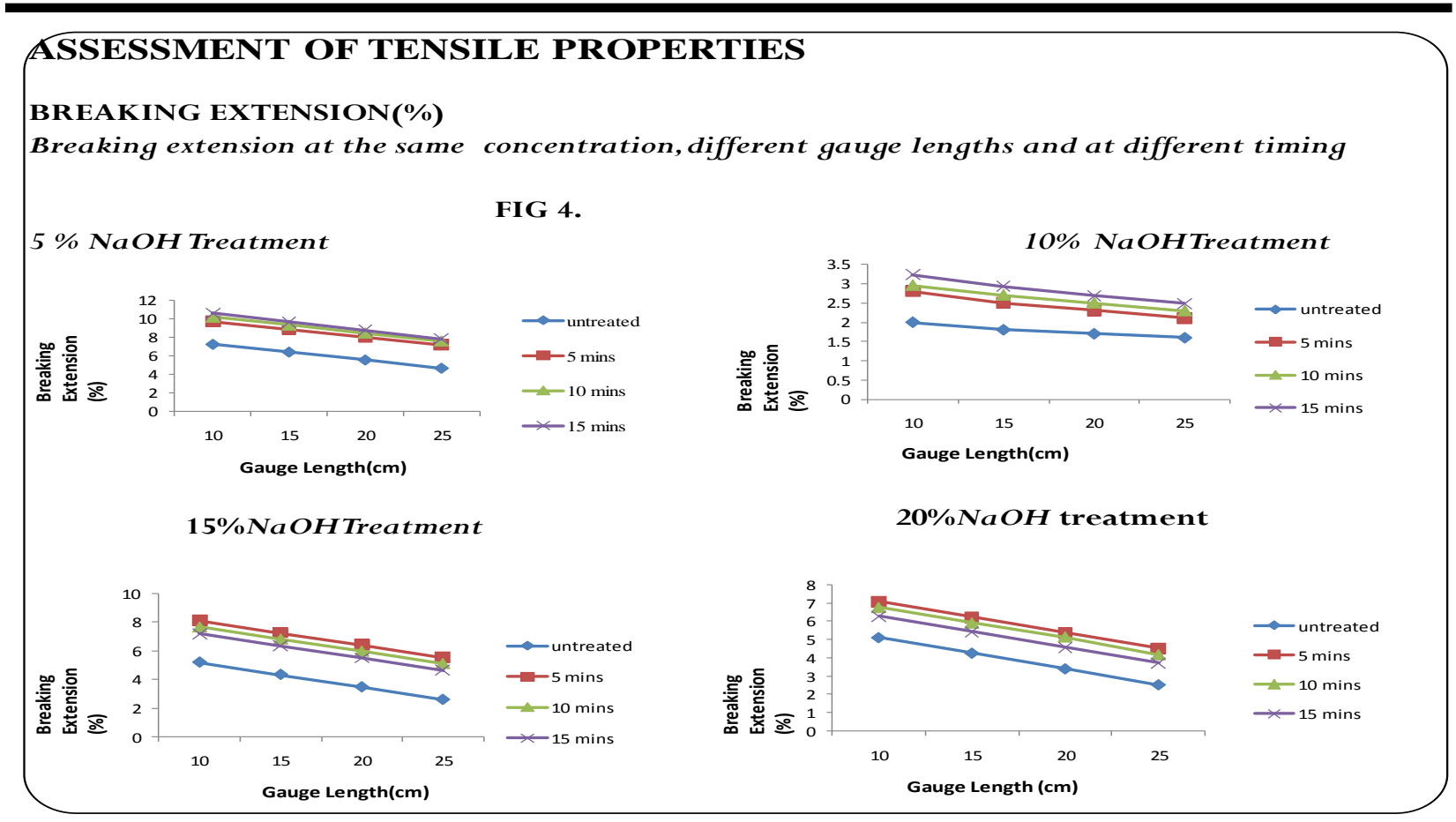

Figure 4: Breaking Extension at same concentration of $\mathrm{NaOH}$, different gauge lengths at different time.

\subsection{INITIAL YOUNG'S MODULUS}

\section{(Young's modulus at different concentration, different gauge length, but at constant time)}

Figure 5 indicate the fact that the untreated sisal fibre has a high modulus compared to the treated ones. Therefore, the modified samples have low modulus as increase in concentration of $\mathrm{NaOH}$ reduces the modulus. A high modulus indicates less extensibility and a low modulus great extensibility. Therefore, modification increases the extensibility of the fibres, while the untreated ones are less extensible. The initialmodulus for both the modified and unmodified fibres decreases with increasing gauge length also due to weak link effects. 
Journal DOI: 10.46654/ij.24889849

Vol. 6, Issue 10 (October, 2020) | www.ijaar.org

Article DOI: 10.46654/ij.24889849.e6105

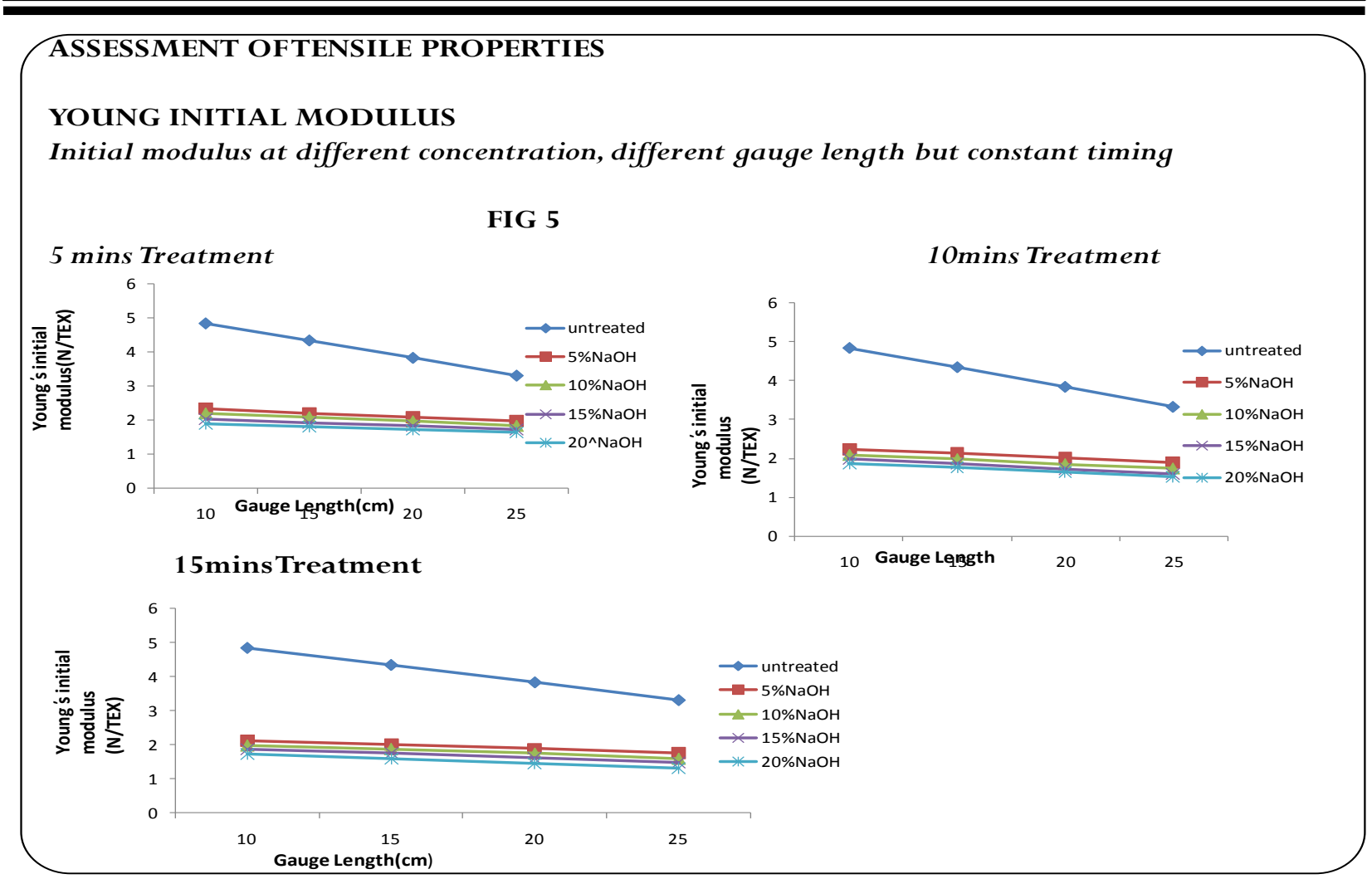

Figure 5: Initial modulus at different concentration of $\mathrm{NaOH}$, different gauge lengths at constant time

\subsection{YOUNG'S INITIAL MODULUS}

(Initial modulus at constant concentration, different gauge length, and at different time)

The graphs of figure 6 are similar to the graphs of different concentration; however increase in time has less effect compared to that of the increase in concentration. 
Journal DOI: 10.46654/ij.24889849

Vol. 6, Issue 10 (October, 2020) | www.ijaar.org

Article DOI: 10.46654/ij.24889849.e6105

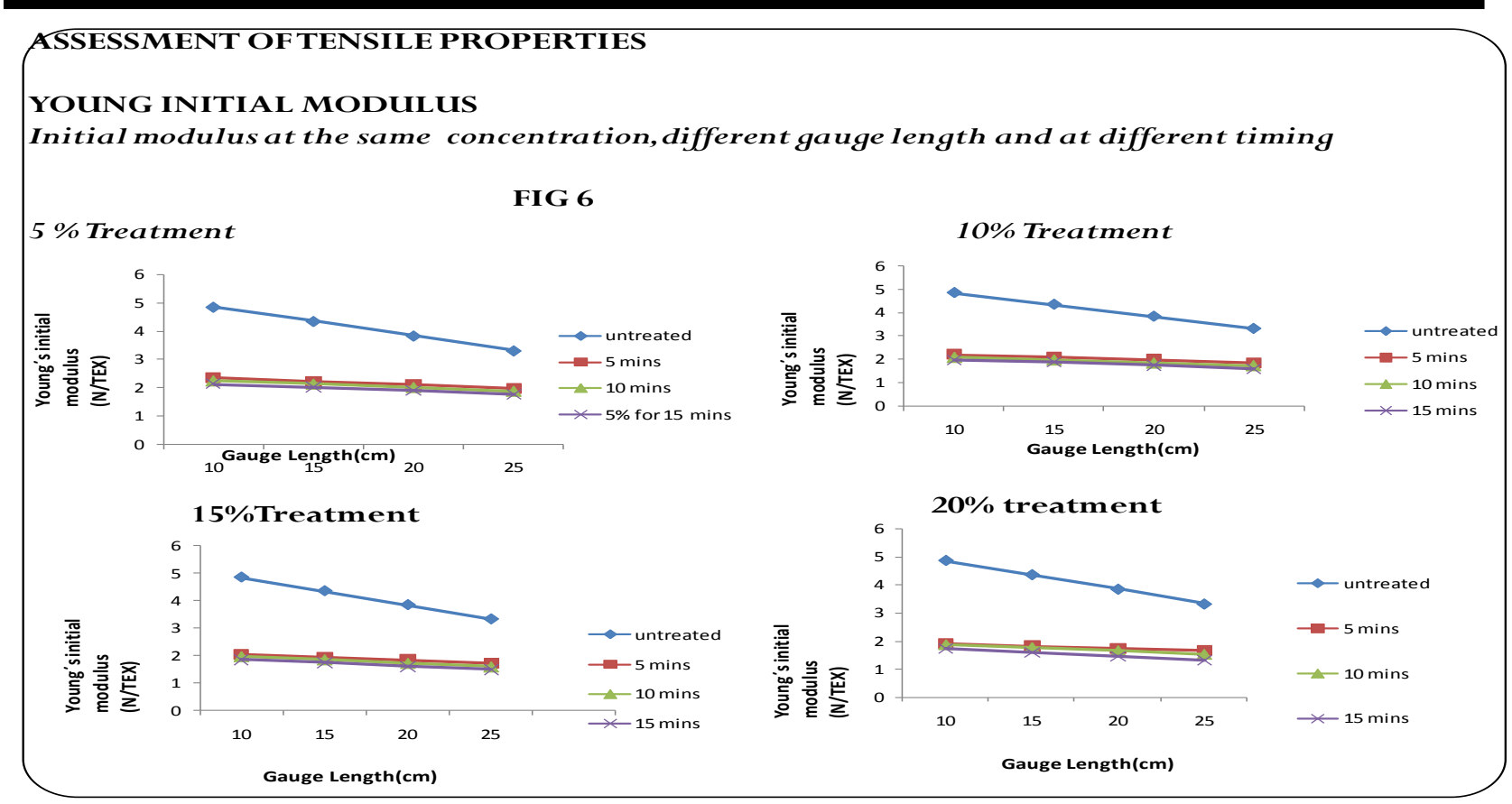

Figure 6: Initial modulus at same concentration of $\mathrm{NaOH}$, different gauge lengths at different time

\subsection{WORK OF RUPTURE}

(The work of rupture at different concentration, different gauge length, and at constant time)

Figure 7 shows that the modified samples have higher work of rupture compared with the unmodified ones. The work of rupture for both the unmodified and modified samples decreased with increase in gauge lengths also due to weak link effect. Hence, the higher the modification (higher concentration of caustic soda), the higher the work of rupture.

Work of rupture, a measure indicating the ability to absorb work, is an important property of textile fibres. Good strength combined with elongation gives a high work of rupture, which enables the fibres to withstand sudden impacts. Thus the modified samples with the highest work of rupture are expected to absorb sudden impact more conveniently than the other fibre samples. 
International Journal of Advanced Academic Research (Sciences, Technology and Engineering) | ISSN: 2488-9849

Journal DOI: 10.46654/ij.24889849

Article DOI: 10.46654/ij.24889849.e6105

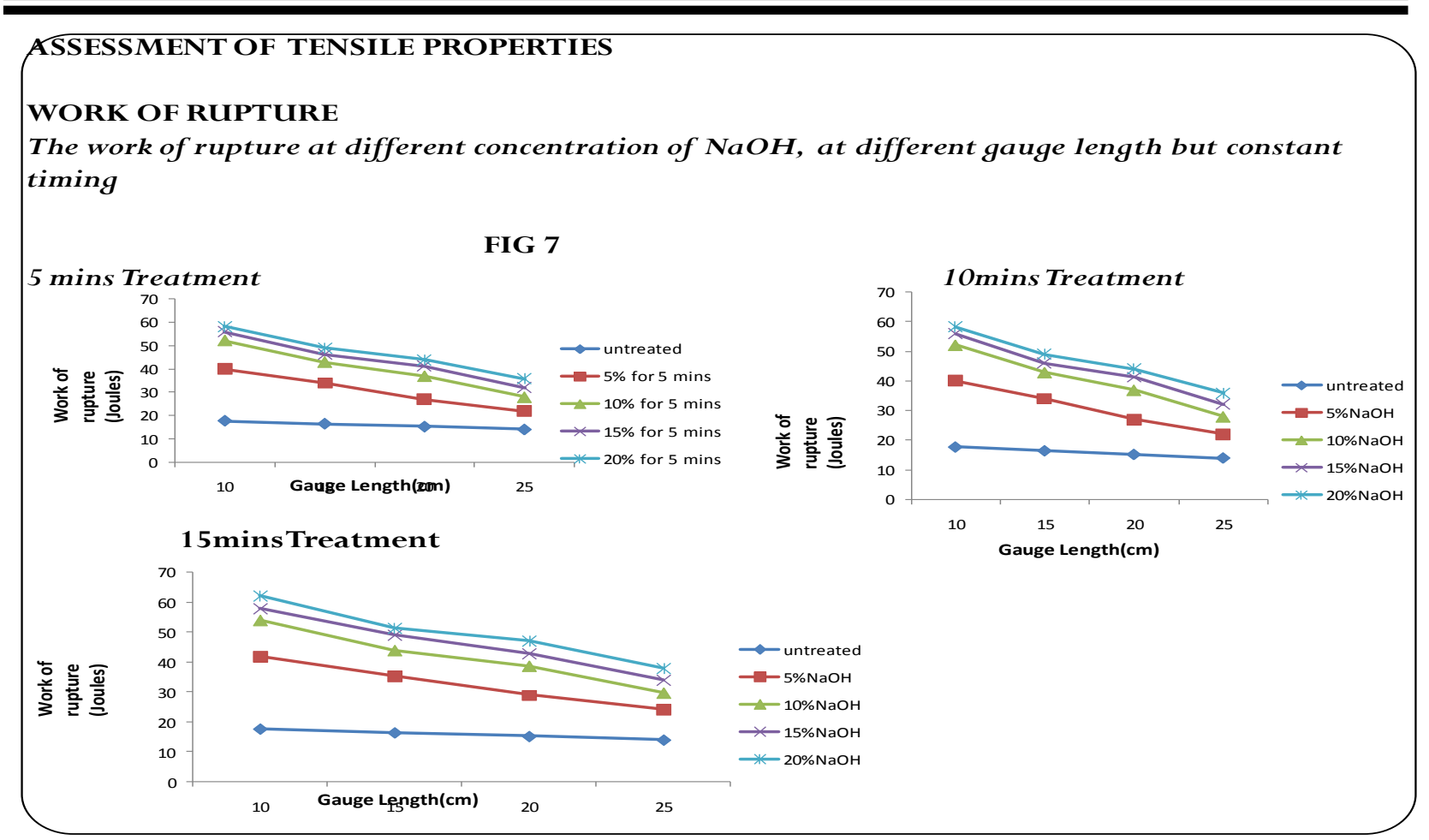

Figure 7: work of rupture at different concentration of $\mathrm{NaOH}$, different gauge lengths at constant time

\subsection{WORK OF RUPTURE}

\section{(The work of rupture at constant concentration, different gauge length, and at different time)}

The graphs are similar to the ones of increase in concentration, but increase in time has very little effects on the work of rupture during modification. 
Journal DOI: 10.46654/ij.24889849

Vol. 6, Issue 10 (October, 2020) | www.ijaar.org

Article DOI: 10.46654/ij.24889849.e6105

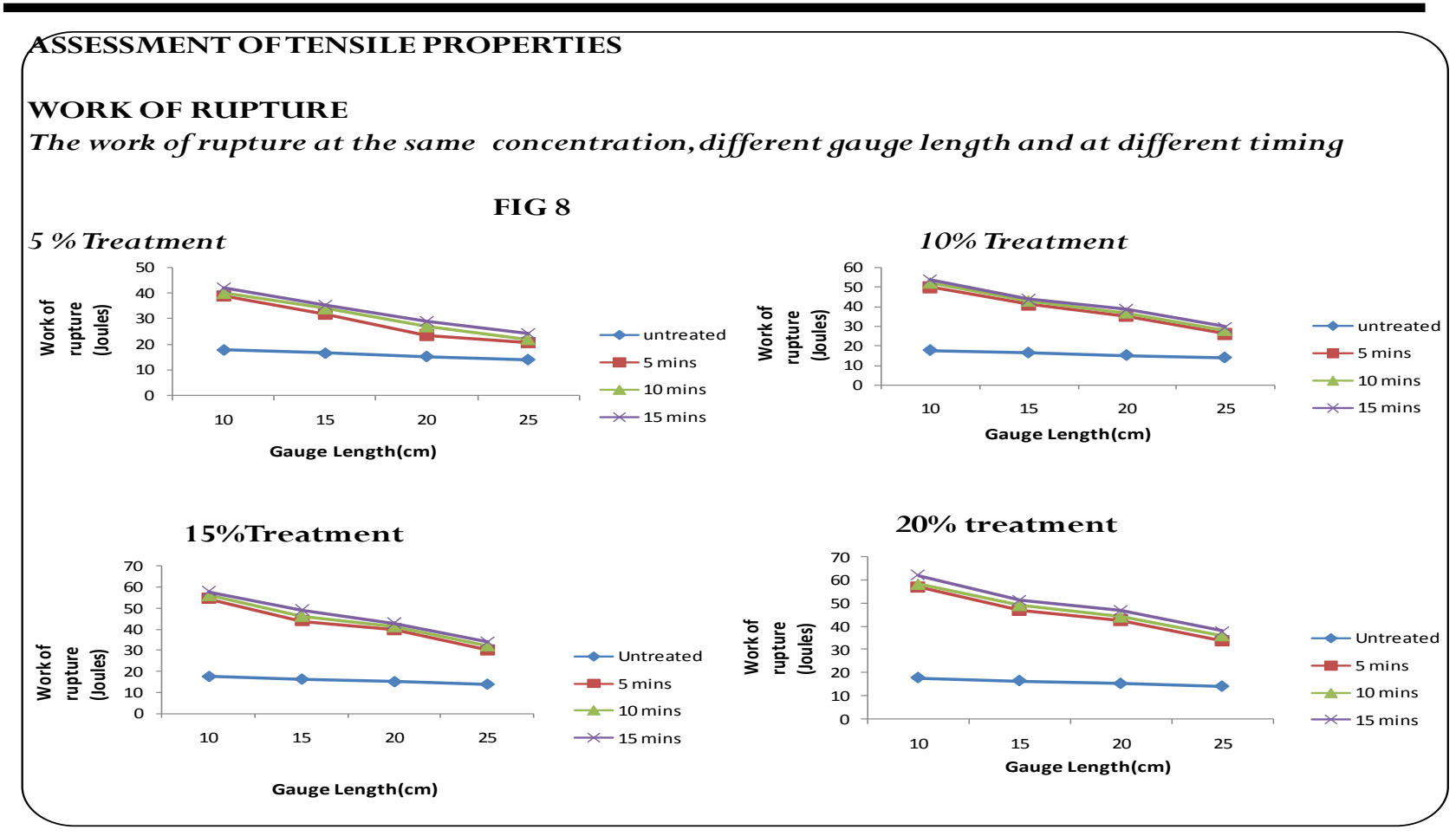

Figure 7: Work of rupture at same concentration of $\mathrm{NaOH}$, different gauge lengths at different time

\section{CONCLUSION}

The results obtained from the tensile properties of the sisal fibres can be summarized as follows:

Increase in concentration of caustic soda, reduces the Young's modulus but increases the tenacity, breaking extension and work of rupture of the sisal fibres.

Increase in the time of modification has no marked effect on the tensile properties of the sisal fibres as compared to the increase in concentration of $\mathrm{NaOH}$. Increase in gauge length, causes thesetensile properties to decrease. This is due to "weak link effect".

It can therefore, be concluded that alkali modification has significant effects on the tensile properties of sisal fibres. 


\section{REFERENCES}

Abdelmouleh, M., Boufis, S., Belgacem, M.N., and Dufresne, A. (2007). Short natural-fibre reinforced polyethylene and natural rubber composites:

Effect of silanecoupling agents and fibre loading.Composite Science and Technology, 67(7-8), 1627-1639

Joseph, K., Mattoso, L.H.C., Toledo, R.D., Thomas, L.H., de Carvalho, L., Pothen, S. and Kala.(2000). UNESP, 159.

Mishra, S., M. Misra, S.S., Tripathy, S.K., Nayak.F.andMohantY, A.K. (2002). Polym. Compos., 23, 164

Morrison, W.H., Archibald, D.D, Sharma, K. and Akin, B. (2000).lnd.Crop.Prod.12, 39.

Sreekala M.S, Kumaran, M.G., Joseph, S., Jacob, M. and Thomas, S. (2001).Appl. Compos.Mater., 7, 295

Tserki, V., Zafeiropoulos, N.E., Simon, F., and Panayiotou, C. (2005).A study of the effect of acetylation and propionylation surface treatments on natural fibres.Composites : Part A, 36(8), 1110-1118.

Ye, L. and Mai W. (2000), Composites Sci. Technol., 60, 37. 